\title{
O conceito de tonalidade segundo François- Joseph Fétis: tradução comentada de um artigo de divulgação de Robert Wangermée ${ }^{1}$
}

The concept of tonality according to FrançoisJoseph Fétis: commented translation of a science popularization article by Robert Wangermée

Sérgio Paulo Ribeiro de Freitas ${ }^{2}$ Edilamar Ilha Librelotto ${ }^{3}$ 


\section{Resumo}

Quem foi François-Joseph Fétis? Qual a relação deste personagem, ilustre e desconhecido, com o termo "tonalidade" que atualmente empregamos tão corriqueiramente? Quais as principais repercussões de suas análises e concepções? Como suas contribuições afetaram ou ainda afetam os campos da crítica, da musicologia e da pedagogia musical? Procurando respostas para perguntas deste tipo, apresenta-se aqui uma tradução comentada de um artigo de divulgação, publicado originalmente na Revue Belge de Musicologie em 1998, de autoria de Robert Wangermée, um dos mais destacados estudiosos da vida e obra de François-Joseph Fétis. Contextualizando o personagem em seu tempo, o texto traça um perfil biográfico de Fétis, dá noção de sua impressionante produção bibliográfica, sumariza sua compreensão da noção de tonalidade e descreve, em linhas gerais, os fundamentos do sistema de quatro ordens - unitônica, transitônica, pluritônica e omnitonica - elaborado por este que já foi considerado um dos mais influentes teóricos musicais da primeira metade do século XIX ou mesmo um dos mais importantes estudiosos musicais de todos os tempos.

Palavras-Chave: Tonalidade; François-Joseph Fétis; Teoria Musical.

\section{Abstract}

Who was François-Joseph Fétis? What is the relation between this honorable and unknown character and the nowadays routinely used term "tonality"? What are the main implications of his analysis and conceptions? How did his contributions affect or how do they still affect the fields of critique, musicology and music pedagogy? The current study presents a commented translation of a science popularization article originally published in Revue Belge de Musicologie (Belgian Musicology Journal) in 1998, by seeking the answers to these questions. The article was written by Robert Wangermée, one of the most prominent scholars of the life and work of FrançoisJoseph Fétis. The text traces a biographical profile of Fétis by contextualizing the character in his time, approaches his impressive bibliographic production, summarizes his understanding of tonality and describes, in general terms, the fundamentals of the four orders system (unitonic, transitonic, pluritonic and omnitonic harmonic orders) created by Fétis, who was once considered one of the most influential musical theorists of the early nineteenth century or even one of the most important musical scholars of all times.

Keywords: Tonality; François-Joseph Fétis; Music Theory.

ISSN: $1808-3129$

\footnotetext{
${ }^{1}$ Trata-se de uma tradução comentada do artigo WANGERMEE, Robert. Le concept de tonalite selon Fetis. Revue belge de Musicologie / Belgisch Tijdschrift voor Muziekwetenschap, Vol. 52, 1998, pp. 35-45. Publicação da Societe Belge de Musicologie.

${ }^{2}$ Sérgio Paulo Ribeiro de Freitas sergio.freitas@udesc.br

${ }^{3}$ Edilamar llha Librelotto edilamarlibrelotto@gmail.com
} 


\section{Apresentação}

A Harmonia existe na natureza, e contudo o ouvido dos Turcos, Árabes e Chinas ainda até hoje se não pôde acostumar a ela.

(F. J.FÉTIS, 1858, p. 85)

Consultando obras de teoria musical e harmonia na biblioteca de nossa escola, alguns estudantes encontraram um raro exemplar de " $A$ música ao alcance de todos. Ou noticia succinta de tudo o que é necessário para ajuizar e fallar d'esta arte sem a ter profundado", livro publicado na cidade do Porto, Portugal, em 18584. Este livro, desde o próprio título, traz afirmações categóricas - como a que se destaca acima em epigrafe - que, em tempos atuais, fomentam indagações necessárias: quem, quando, onde e porque alguém escreveria algo assim $?^{5}$

O autor deste "A música ao alcance de todos" é o célebre professor, editor, compositor, crítico e historiador belga François-Joseph Fétis (1784-1871), um personagem obrigatório no mundo da musicologia, posto que "foi possivelmente o teórico mais influente da primeira metade do século XIX e certamente um dos mais importantes estudiosos musicais de todos os tempos" (SIMMS, 1975, p. 112) ${ }^{6}$. Dentre diversos méritos, como se sabe, por um bom tempo coube ao prolífico F. J. Fétis o crédito de ter sido "o primeiro" a empregar o influente vocábulo "tonalidade". A questão sobre quem teria sido o proponente deste que se tornou um incontornável "termo específico da metalinguagem da musicologia" (NATTIEZ, 1984, p. 335) vem ocupando razoável atenção.

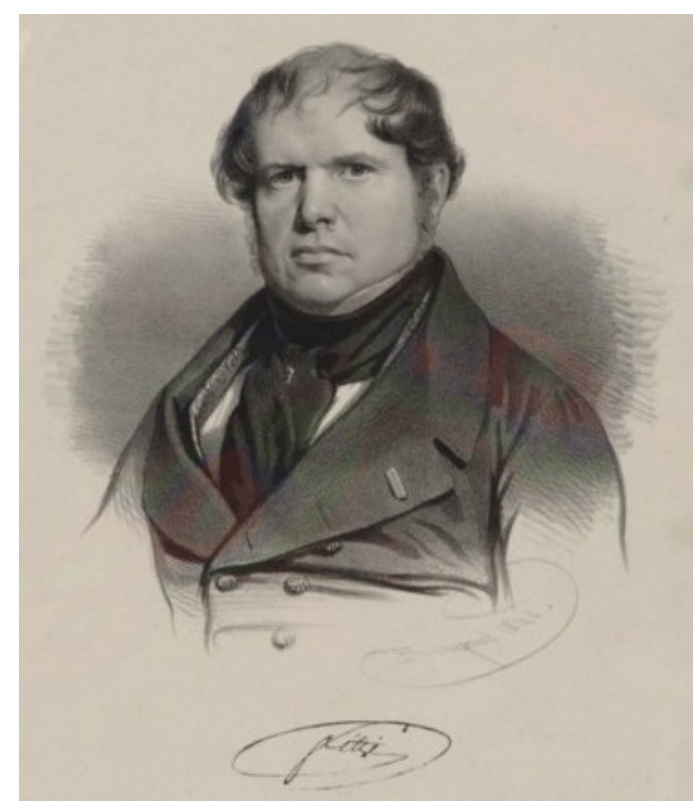

Fig. 1 - François-Joseph Fétis

(1784-1871). Retrato editado em 1841. Fonte: Bibliothèque Nationale de France. Domínio Público.

\footnotetext{
${ }^{4}$ Como "La musique mise à la portée de tout le monde: exposé succinct de tout ce qui est nécessaire pour juger de cet art, et pour en parler sans l'avoir étudié" o livro doi publicado pela primeira vez em Paris no ano de 1830. Logo surgiram versões em alemão, inglês, russo e espanhol. A tradução para o português foi realizada pelo organista e professor portuense José Ernesto D'Almeida (1807-1869) em 1845.

5 Desde já, vale recuperar o comentário de Gubernikoff (2012, p. 169): "Lendo os textos de Fétis encontramos um vocabulário inaceitável para os dias de hoje, mas coerente com evolucionismo e o historicismo dominantes, quando se referia aos povos 'bárbaros' e 'primitivos'"

6 Fétis atuou em diversos campos do conhecimento musical, conforme mostra o abrangente mapeamento bibliográfico organizado por Schellhous (1991, p. 219-220).
} 
Consultando autores que se debruçaram sobre tal questão - tais como Brown (2005, p. xiii), Christensen (1996, p. 37-41), Corrêa (2006, p. 22-23), Dahlhaus (1980), Hyer (2006, p. 729-730), Simms (1975, p. 119), Wason (1995, p. 102-103) -, em linhas gerais se observa que o termo tonalité circulava no meio musical parisiense quando o jovem Fétis ali vivia. Em registro impresso, o termo tonalité encontra-se no "Sommaire de l'histoire de la musique" que abre o "Dictionnaire historique des musiciens, artistes et amateurs" publicado, entre 1810 e 1811 e revisado em 1817, pelo historiador, compositor, pedagogo e teórico musical francês Alexandre-Étienne Choron (17711834) em parceria com o, nem sempre citado, escritor e estudioso musical francês François-Joseph-Marie Fayolle (1774-1852)7. Frequentemente se menciona também o destaque dado ao termo tonalité, em publicação de 1814, numa nota de rodapé que Choron, agora como tradutor, acrescentou ao "Méthode élémentaire de composition" publicado em 1790 pelo professor, compositor e teórico austríaco Johann Georg Albrechtsberger (1736-1809) ${ }^{8}$. Destes anos data também o verbete "tonalité" que se encontra no "Dictionnaire de musique moderne", publicado em 1821, pelo crítico musical, compositor e editor francês François-Henri Castil Blaze (1784-1857). Neste ínterim e de modo extensivo, Fétis conceitua o termo em seu "Traité complet de la théorie et de la pratique de l'harmonie" concluído, segundo consta, em 1816, mas publicado apenas em 1844.

No presente artigo de divulgação "Le concept de tonalite selon Fetis", que aqui é objeto de tradução, Robert Wangermée (1998) não debate a questão da primazia9. Dá crédito a Fétis e concentra-se mais propriamente na conceituação apresentada pelo teórico procurando situar o personagem em seu tempo. Vale reiterar - com Nattiez (1984, p. 256) - que "o imenso mérito" de Fétis foi o de se "recusar a basear a harmonia numa lei natural". Tais "leis" são intrassistêmicas, i.e., são "leis de arte", "leis do ofício da harmonia", e não "leis" fisicalistas, matematicistas que elevam a "série harmônica" à condição de paradigma científico, universal e transcendental. As harmonias são regidas pelas "leis" do homem e seus "segredos" decorrem das práticas culturais. Conforme aborda Wangermée no presente artigo, o argumento cultural historicista de F. J. Fétis - em alguma medida "inspirado pela concepção hegeliana de Weltgeist (Espírito do Mundo)" (LOYA, 2011, p. 155) ${ }^{10}$ - é o de que o desenvolvimento da tonalidade europeia se deu através de uma sucessão de etapas periodicamente determinadas designadas então como as "quatro ordens da tonalidade", conforme o

\footnotetext{
7 Vale notar que o termo tonalité é consideravelmente corrente ao longo deste dicionário. O título completo da obra é "Dictionnaire historique des musiciens, artistes et amateurs, morts ou vivans: qui se sont illustrés en une partie quelconque de la musique et des arts qui y sont relatifs, Tels que Compositeurs, Écrivains didactiques, Théoriciens, Poêles, Acteurs lyriques, Chanteurs, Instrumentistes, Luthiers, Facteurs, Graveurs, Imprimeurs de musique, etc.; avec des renseignemens sur les Théâtres, Conservatoires, et autres établissemens dont cet art est i'objet. Précédé d'un Sommaire de l'histoire de la musique".

8 Na versão de 1817 o título da obra é "Méthode élémentaire de composition. Avec des exemples très-nombreux et très-étendus pour apprendre soi-même à composer toute espèce de musique". Na publicação de 1790, o título desta obra de Albrechtsberger é "Gründliche Anweisung zur Composition mit deutlichen und ausführlichen Exempeln, zum Selbstunterrichte, erläutert; und mit einem Anhange: Von der Beschaffenheit und Anwendung aller jetzt üblichen musikalischen Instrumente."Albrechtsberger é lembrado como compositor, pedagogo, teórico e organista, amigo de Mozart e professor de contraponto de Beethoven entre 1794 e 1795, reconhecido pelo notável esforço de organização das teorias musicais do século XVIII.

9 Robert Wangermée, nascido em 1920, é um musicólogo belga. Paralelamente à sua atuação acadêmica, fez carreira também no campo do audiovisual: atuou no INR (Institut National de Radiodiffusion) e na Radio Télévision Belge Francophone - RTBF. Autor de livros, artigos e numerosos prefácios. Atua ainda como editor ou coloborador em inúmeras publicações nas áreas da musicologia, da sociologia da música, das políticas culturais e da radiodifusão. É autor de um amplo estudo biográfico sobre Fétis (WANGERMÉE, 1951) e organizou e publicou sua correspondência (WANGERMÉE, 2006).

10 Ponderando a argumentação legalista de Fétis e seus epígonos, considera-se que, por analogia, as "quatro ordens" pretendem assumir o papel finalista de "Espírito do Mundo" (Weltgeist), ou seja, "de guia e sujeito único da história". Conforme Abbagnano (1982), em Hegel "esse Espírito do Mundo conforma-se ao Espírito Divino, que é o Espírito Absoluto. Assim como Deus é onipresente, está em todos os homens, aparece na consciência de cada um, isso é o Espírito do Mundo". Ainda conforme Abbagnano, de maneira otimista, a noção de Espírito do Mundo "foi muito repetida e em geral se encontra em todas as concepções providencialistas de história".
} 
esquematizado na Fig.2.

Ainda que bastante problematizada, ${ }^{11}$ em certa medida, este tipo de logicidade linear e etapista ainda ressoa no ensino da harmonia. E não se deixa notar somente aí: acreditando que "a história da música ocidental apresenta um alargamento constante do sentido harmônico e, com isso, um aumento da tolerância da sensibilidade auditiva para a dissonância" (SANTAELLA, 2001, p. 179), seguimos acreditando que este tipo de arranjo teleológico nos afeta de maneira mais ampla. Então, naturalizando o discurso finalista de que a história da música pode ser contada como um "desenvolvimento cronológico das consonâncias" (CHAILLEY, 1947, p. 15), aprendemos a defender que, neste "desenvolvimento", a imanência do simples para o complexo determina o curso que vai da renascença ao pós-romântico. Ou em outros termos: argumentando que o progresso do diatônico para o cromático determina o caminho do pré-tonal ao pós-tonal, reiteramos a "grande narrativa tonal" (LOYA, 2011, p. 154-157) que, devidamente reforçada pelas diversas teorias formais da tonalidade, alimenta nossas concepções de o que incluir e em que ordem devemos organizar e valorar os conteúdos a serem ensinados e aprendidos em nossos programas de formação cultural e de ensino e aprendizagem musical.

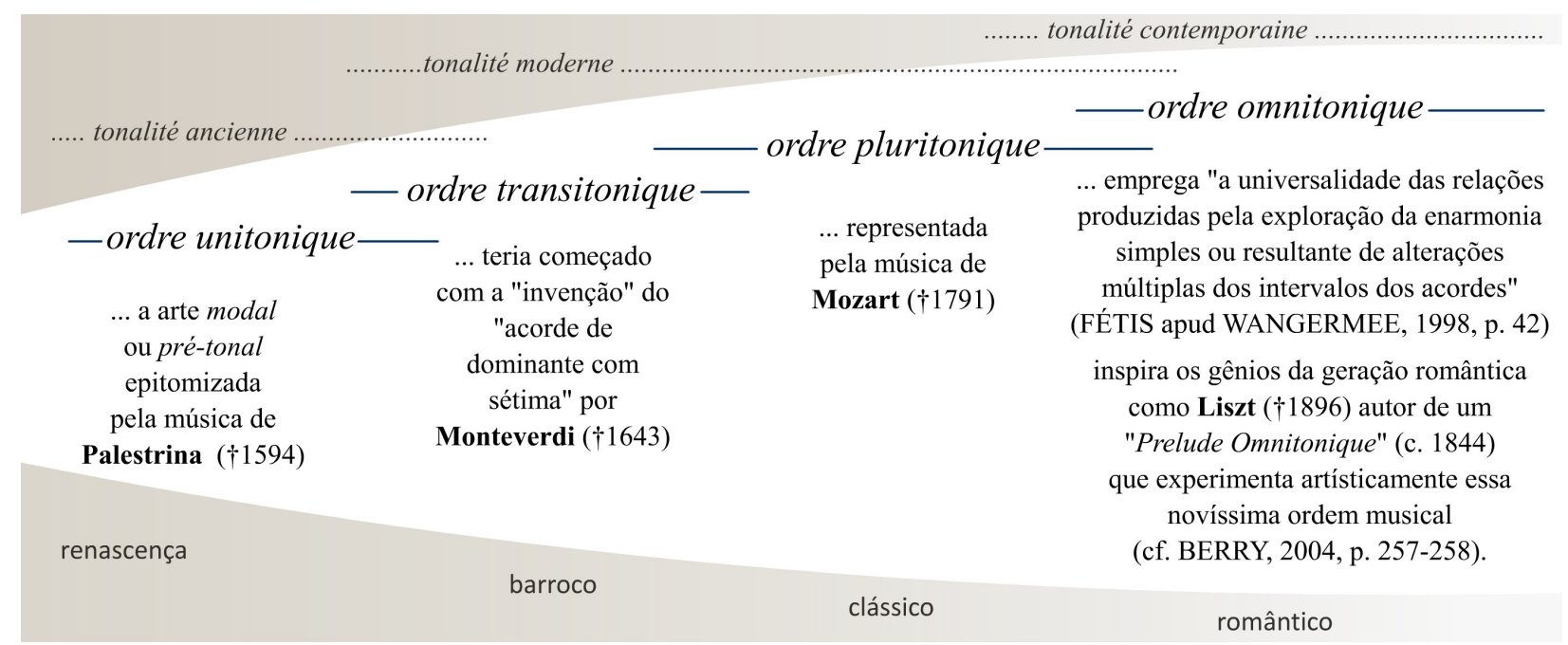

Fig. 2 - Visualização geral das "quatre ordres" da tonalidade propostas por Fétis.

Concluindo este preâmbulo, vale acrescentar que o presente exercício de tradução comentada decorre de rotinas que, na sala de aula de teoria musical, visam enfrentar a questão da diversidade de perfis dos estudantes em nossas universidades. Alguns estudantes possuem proficiência em língua estrangeira, e esta experiência pode ser potencializada contribuindo para ampliar o alcance cultural da disciplina e, ao mesmo tempo, favorecer a interação e a sociabilidade entre os diferentes estudantes e suas desiguais histórias de vida ${ }^{12}$.

Outro aspecto que motiva o presente exercício, na perspectiva já apontada por Priore (2013), diz respeito ao fato de que a leitura e a reescrita de textos como este

11 Dentre diversos autores que abordam a tese das "quatre ordres" defendida por Fétis, ver Arlin (1973, p. 111-112), Berry (2004, p. 253-257), Christensen (1996, p. 50-53; 2014), Dahlhaus (1990, p. 12-13), Damschroder (2008, p. 174-176), Kosar (1984), Loya (2011, p. 155-1570, Mickelsen e Riemann (1977, p. 186); Móricz (1994, p. 405-416); Saslaw (1992, p. 360), Shirlaw (1969, p. 335-351), Simms (1975) e Wason (1995, p. 104).

12 Neste caso, trata-se da disciplina Teoria Musical ministrada pelo professor Sérgio Paulo Ribeiro de Freitas nos cursos de música da Universidade do Estado de Santa Catarina ao longo do primeiro semestre de 2014. Edilamar Ilha Librelotto, à época aluna da disciplina, prontamente aceitou a proposta que resultou na presente versão do artigo de autoria de Robert Wangermée. 
podem fomentar uma espécie de redesenho da disciplina entre os estudantes e, muitas vezes, entre o próprio corpo docente. Então, as tarefas envolvidas na atividade de tradução podem concorrer para um redimensionamento das funções, capacidades e esferas de atuação e de interação que a teoria musical, enquanto campo de conhecimento musicológico, efetivamente possui em âmbito internacional atualmente. Este redimensionamento pode trazer novo ânimo ao dia a dia da disciplina apontando perspectivas novas ou desconhecidas de formação acadêmica e de atuação profissional para nossos educandos. Por fim, vale ressaltar que, ao lidar com personagens, concepções e referências que perpassam os séculos, do renascimento ao contemporâneo, estes exercícios reavivam a necessidade de investimentos em tradução em nossa área.

\section{"O Conceito de tonalidade segundo Fétis" por Robert Wangermée}

Foi Fétis quem, primeiramente, introduziu o conceito de tonalidade na reflexão sobre a harmonia. Sabe-se que François-Joseph Fétis foi, no período de 1833 a 1871, o primeiro diretor do conservatório de Bruxelas. Mas Fétis possui muitos outros méritos. Nasceu em Mons [Bélgica] em 1784; e dado que, à época, os Países Baixos austríacos estavam integrados à França, de 1800 em diante prosseguiu seus estudos no Conservatório de Paris que tinha acabado de ser criado e que exercia uma atração considerável em virtude de um ensino renovador ${ }^{13}$. No Conservatório cursou as cadeiras de harmonia, contraponto e fuga; em 1821 foi nomeado professor de composição e, de 1825 a 1831, atuou como bibliotecário da instituição. Na época, ficou conhecido como um professor de grande autoridade, como um compositor honorável e como um temido crítico musical. Fétis toma então uma iniciativa audaciosa: a publicação, a partir de 1827, de um periódico especializado, a Revue musicale (Revista musical) ${ }^{14}$. Fétis incumbiu-se de tudo, desde a organização material e comercial de sua revista até a redação, sozinho, deste semanário de 24 a 32 páginas. Encontra-se aí o seu ponto de vista sobre a atualidade musical parisiense, informações sobre a vida musical na Europa, investigações originais, ensaios históricos, estéticos ou técnicos, notadamente sobre orquestração e harmonia ${ }^{15}$.

Em sua partida para Bruxelas ${ }^{16}$, Fétis trabalhou intensamente em uma importante obra, a Biographie universelle des musiciens (Biografia universal dos músicos), cuja primeira edição, em 8 volumes, surgiu em $1835^{17}$. Ele mesmo redigiu todos os verbetes explorando a enorme documentação que acumulou ao longo de anos, con-

\footnotetext{
13 Nota dos tradutores (doravante NT). Considera-se que o Conservatoire de Paris foi fundado em 1795, assim, no contexto das ações que decorrem da Revolução Francesa e chegam a modificar a cena musical europeia (cf. BINGHAM, 1966; SQUEFF, 1989, p. 119-123), observa-se que Fétis está ligado ao ambiente teórico pedagógico que floresce na França no decorrer do século XIX demarcando a institucionalização da Harmonia como uma disciplina de Conservatório. Neste momento, tal fato significou uma positiva socialização e decorrente popularização dos conhecimentos musicais, permitindo ao comum dos homens, através da instituição dessas escolas de ofício, um acesso público aos segredos de uma arte até então mais reservados. Com isso, a institucionalização da disciplina contribuiu também para sua propagação intercontinental. Dos recantos das Américas partiam os mais notáveis talentos para estudar nesses centros de formação musical europeia. Note-se por exemplo que, mais tarde, já no Conservatoire royal de Bruxelles, Fétis foi professor do compositor, regente e violinista brasileiro Manuel Joaquim de Macedo que, em 1871, retorna ao Brasil e, nomeado por Pedro II, ocupou o posto de Mestre da Capela Imperial no Rio de Janeiro e, posteriormente, estabeleceu-se em Minas Gerais deixando alunos que, por seu turno, deram importante contribuição ao ensino da música neste estado (cf. REIS, 1993, p.132). 14 NT. Os números da Revue musicale publicados entre 1827 e 1835 foram reunidos e republicados por Cloutier (1991).

15 Nota do autor (doravante NA). Cf. WANGERMEE, Robert. François-Joseph Fétis, musicologue et compositeur. Contribution a l'étude du goût musical au xixe siècle (Bruxelles, 1951; "Memoires de la Classe des Beaux-Arts de l'Académie royale de Belgique").

16 NT. Fétis permaneceu em Paris até 1833 quando, a convite de Leopold I, tornou-se diretor do Conservatoire royal de Bruxelles e Mestre de Capela do Rei da Bélgica. Cf. Damscrhroder (1990, p. 85).

17 NT. A Biographie universelle de Fétis está disponivel em International Music Score Library Project.
} 
tando com uma rede de informantes em toda Europa. Nesta Biographie universelle, Fétis não se limita a estabelecer dados bio-bibliográficos, fornece detalhes técnicos sobre as obras e tece julgamentos sobre os músicos do passado e do presente. Para equilibrar o caráter analítico dos verbetes, apresenta à guisa de introdução um "Resumo filosófico da história da música", com mais de 250 páginas, no qual a música é considerada uma linguagem autônoma que se transforma na linha do tempo.

Fétis foi iniciado ao passado musical através da leitura das histórias gerais estabelecidas no século precedente por Burney ${ }^{18}$ e Forkel ${ }^{19}$ e também pelo estudo dos tratados teóricos de contraponto e fuga que, seguindo o Gradus ad Parnassum de Fux ${ }^{20}$, continuaram a incluir exertos de missas e motetos polifônicos do século XVI como exemplos de escrita rigorosa. Estudando os velhos tratados, Fétis compreendeu que tais obras não eram somente modelos de escrita. Estudando textos de teóricos alemães, como Marpurg ${ }^{21}$, Albrechtsberger ou Kirnberger22, percebeu que as peças de Georg Friedrich Händel ou Johann Sebastian Bach, citadas a título de exemplos, continham mais emoção e beleza que muitas obras posteriores. Assim Fétis suspeita da lei, que até então parecia assegurada, do progresso necessário para a arte da música ${ }^{23}$. Com isto, Fétis decide voltar às fontes primárias: estudar os mestres do passado em textos originais (que, frequentemente, ele mesmo tinha que transcrever),

18 NT. Charles Burney (1726-1814), compositor e erudito historiador britânico que, dentre outras obras, escreveu a General history of music from the earliest ages to the present period (História geral da música das eras mais remotas até o período presente) publicada em Londres entre 1776 a 1789 e tida como "uma das primeiras grandes histórias da música” (DAHLHAUS, 1999, p. 7). A fim de pesquisar e colher dados para seus trabalhos, Burney, já doutor em música pela Universidade de Oxford, viajou por toda a Europa. Nas diversas cidades por onde passa, ouve música nas igrejas, nos teatros, conservatórios, percorre bibliotecas, encontra-se com músicos famosos, compositores, instrumentistas e cantores. Sobre esse célebre giro musical de Burney pelo centro da Europa, cf. Gonsalves (1934).

19 NT. O erudito alemão Johann Nikolaus Forkel (1749-1818) é lembrado como o primeiro biografo e admirador profissional de Johann Sebastian Bach (16851750). Conforme Benévolo (2003, p. 65-66), o discurso de Forkel em obras como a Allgemeine Geschichte der Musik (História Geral da Música, publicada entre 1788 e 1801), está impregnado do sentido de decadência que o autor percebia em toda a música que veio depois de Bach. Conforme Salazar, em comentário ao trabalho de Forkel, Über Johann Sebastian Bachs Leben, Kunst und Kunstwerke (Sobre a vida, arte e obras de Johann Sebastian Bach, 1802), Forkel presenciou o apogeu dos clássicos e a aparição do acento romântico. Adorador do antigo - e cego à toda inovação -, Forkel exaltou o barroco de Bach, cuja majestosa polifonia considerou exemplo perene da ciência e arte musical, de gosto depurado e de perfeição eterna alcançada pela persistente exigência que a si mesmo Bach se impunha. Outro aspecto a ser considerado, que não escapa a Salazar, é o fato de que em sua maturidade Forkel escreve numa Alemanha que atravessa uma crise de nacionalismo, assim seus escritos carregam sempre uma paixão patriótica, que em parte matizam e em parte distorcem seus juízos e opiniões (SALAZAR, 1993, p.11). Os tons patrióticos dos elogios de Forkel vão contribuir para a deificação do nome de Bach como a raiz verdadeiramente nacional da linhagem pura dos grandes compositores alemães que se elevam acima de todos os demais e representam a tradição da grande, erudita e universal tonalidade harmônica (cf. DAHLHAUS, 1999, p. 116-124; RUEB, 2001, p. 47-51).

20 NT. Trata-se do compositor, mestre de capela e teórico vienense Johann Joseph Fux (1660-1741). Seu tratado "Gradus ad Parnassum", escrito em latim, foi publicado em 1725. Traduzido ao alemão, em 1742 por Lorenz Mizler (um ex-aluno de J. S. Bach), "foi utilizado por Haydn, Mozart, Beethoven e Schubert, tanto para estudar quanto para ensinar", "muito metódico e racional, Gradus ad Parnassum é o modelo de todos os tratados de contraponto subsequentes até o segundo terço do século XX" (ABROMONT e MONTALEMBERT, 2001, p. 450-451). Abromont e Montalembert também destacam que, embora Fux seja normalmente dado como o proponente da renomada classificação das diferentes espécies do contraponto, esta sistematização está sugerida em trabalhos de autores como Lodovico Zacconi (1555-1627), Girolamo Diruta (II Transivano, 1609, secondo libro) e Adriano Banchiei (Cartela, 1610 e 1614). Ainda segundo Abromont e Montalembert, é provável que Fux tenha baseado seu modelo nos trabalhos de Giovanni Maria Bononcini (Musico prattico, 1673) e Angelo Berardi (Ragionamenti musicali, 1681). 21 NT. Trata-se do crítico, teórico e compositor alemão Friedrich Wilhelm Marpurg (c.1718-1795), de sua lavra atualmente são conhecidas 16 publicações teóricas, referentes a composição e a execução do cravo. Quando jovem conviveu em Paris com personagens como Voltaire e Rameau, em $1751-52$ escreveu o prefácio da primeira edição da "Arte da Fuga" de J. S. Bach e seu "Abhandlung von der Fuge, nach den Grundsätzen und Exempeln der besten deutschen und ausländischen Meister entworfen" (Tratado de fuga concebido de acordo com os princípios e exemplos dos melhores mestres alemães e estrangeiros", publicado em 1753, é considerado uma das primeiras sistematizações da fuga conforme o estilo de J. S. Bach.

22 NT. O teórico e compositor alemão Johann Philipp Kirnberger (1721-1783) é um dos importantes personagens ligados ao desenvolvimento da teoria da harmonia na segunda metade do século XVIII. Seu pensamento teórico, como uma espécie de preanuncio da era clássica, é considerado uma síntese que reúne e reavalia a antiga tradição contrapontística, nesse momento já bastante delimitada pelo trabalho de Fux, a arte do baixo contínuo de viés bachiano e as modernas ideias do baixo fundamental de Rameau (cf. GRANT, 1977; KIRNBERGER, 1979, p. 163-165; LESTER, 2006, p. 773; WASON, 2006, p. 57). Kirnberger é sempre lembrado como aluno de J. S. Bach e deixou vários registros escritos que se tornaram referências significativas para o entendimento atual do pensamento técnico musical da época. Kirnberger também contribuiu com a célebre enciclopédia Allgemeine Theorie der schonen Kiinste (Teoria geral das belas-artes, 1771-74) editada pelo esteta Johann Georg Sulzer (1720-1779)

23 NT. As polêmicas em torno da questão de se saber se, na história da música ocidental, os compositores mais antigos superam os mais recentes, ou viceversa, são polêmicas que se relacionam com uma longa rede de conflitos que, na história da cultura ocidental, é conhecida como La Querelle des anciens et des modernes (a querela dos antigos e dos modernos). A Querelle é um marco do lluminismo e teve seu auge na intervenção, em 1687, do escritor Charles Perrault (1628-1703) que firmou a ideia da supremacia dos modernos em relação à antiguidade clássica pela conclusão de que os modernos são os depositários das experiências milenares, enriquecidas pelas experiências recentíssimas. Sobre a temática cf. Dahlhaus (1999, p. 48-49), Freitas (2010, p. 553-554) e Le Goff (2003). 
situá-los em sua época, retroceder tão longe quanto possível através dos séculos, indo além de Bach, além de Palestrina, até Josquin Desprez, Ockeghem, Dufay, Machaut. Com base na ideia fundamental que expressou de várias formas em muitos de seus escritos, "A arte não progride, ela se transforma", Fétis desejou impor a música antiga ao público organizando, em 1832 e 1833, os Concerts historiques em Paris e, mais tarde, em Bruxelas.

Fazer a história da música, para Fétis, era mostrar o desenvolvimento de sua linguagem e de suas formas. Além de seus cursos no conservatório de Paris, publicou, em 1823, um Méthode elementaire e abrégée d'harmonie e, no ano seguinte, um Traité du contrepoint et de la fugue, mas estes trabalhos não o deixaram satisfeito ${ }^{24}$. Mais do que uma exposição sistemática de regras de escrita, Fétis questionou os próprios fundamentos da harmonia na esperança de encontrar as chaves para a compreensão da linguagem musical e de sua evolução.

Para Fétis as regras não eram impostas pela natureza: elas não poderiam ser deduzidas da ressonância harmônica ou das progressões numéricas. Com lirismo romântico Fétis descreve uma iluminação que lhe ocorreu, em maio de 1831, a respeito da compreensão global do fenômeno musical:

A natureza fornece como elemento da música uma multiplicidade de sons que diferem entre si em altura, duração e intensidade em gradações maiores ou menores. Entre estes sons, aqueles cujas diferenças são sensíveis o suficiente para afetar o órgão da audição de uma maneira determinada, tornam-se o objeto de nossa atenção; a concepção das relações que existem entre estes sons é despertada na inteligência e, pela ação da sensibilidade por um lado e da vontade por outro, o espírito os coordena em séries diferentes, cada um dos quais correspondendo a uma ordem particular de emoções, sentimentos e ideias. Estas séries tornam-se assim os vários tipos de tonalidades e de ritmos que são consequências necessárias, sob cuja influência a imaginação entra em exercício para a criação do belo. ${ }^{25}$

Fétis declara então como, em uma sintética inspiração, pode conceber "o quadro histórico de todas as concepções tonais desde a antiguidade":

Eu descobri os princípios, as causas das transformações e cheguei até o presente, desenvolvendo as condições finais da tonalidade, do ritmo e do acento. Concebo, ao mesmo tempo a classificação das diversas ordens de tonalidade que se sucederam por três séculos pelas afinidades de sons que a harmonia introduziu.

Fétis abordou tal ideia em diversas circunstâncias e sob diversas formas desenvolvendo-a e aprofundando-a. Primeiramente em um curso público de Philosophie musicale et d'histoire de la musique (Filosofia musical e de história da música) que ministrou em Paris, de maio a julho de 1832, e que reuniu a maioria dos músicos curiosos em relação ao significado de sua arte. Liszt, notadamente, esteve presente e guardou uma viva recordação do curso ${ }^{26}$.

\footnotetext{
24 NT. Os títulos completos destas obras são: "Méthode élémentaire et abrégée d'harmonie et d'accompagnement: suivie d'exercices gradués et dans tous les tons, par l'étude desquels les amateurs pourront arriver promptement à accompagner la basse chiffrée et la partition" (1823). "Traité du contrepoint et de la fugue, contenant l'exposé analytique des règles de la composition musicale depuis deux jusqu'à huit parties réelles. Ouvrage divisé en deux parties. La première traitant du contrepoint simple et de ses applications dans l'imitation, le canon et les divers styles. La deuxième, des contrepoints doubles et de la fugue" (1824).

25 NA. "Prefácio" para a quarta edição do "Traité complet de la théorie et de la pratique de l'harmonie contenant la doctrine et la science de l'art" [Tratado completo da teoria e prática da harmonia contendo a doutrina da ciência e da arte]. Paris, Brandus, 1849. p. 11 e 12.

26 NT. Sobre as relações entre a teoria de Fétis e a prática composicional de Liszt, cf. Móricz (1994).
} 
As oito lições foram publicadas em resumo, de semana em semana, na Revue musicale. Cinco anos depois, Fétis deixa a França, instala-se em Bruxelas e consagra o essencial de seu tempo à organização pedagógica do conservatório e também à publicação de sua Biographie universelle des musiciens. Fétis só retoma os seus trabalhos sobre harmonia alguns anos mais tarde. Paralelamente ao exame das obras musicais propriamente ditas, Fétis realiza um estudo aprofundado de todas as obras que, de algum modo, tratavam de harmonia. Sintetiza esta vasta pesquisa (a primeira neste domínio), em um Esquisse de l'histoire de l'harmonie considérée comme art et comme science systématique (Esboço da história da harmonia considerada como arte e como ciência sistemática) publicado em 1840 em quatorze números da Revue et gazette musicale de Paris e, em seguida, reunido em um volume ${ }^{27}$. Em março de 1844, ministra em Paris um curso gratuito de história e teoria da música em quatro lições, que resumiu na Revue et gazette musicalle. E, alguns meses mais tarde, publica - Traité complet de la théorie et de la pratique de l'harmonie contenant la doctrine de la science et de l'art (Tratado completo da teoria e prática da harmonia contendo a doutrina da ciência e da arte), que não é meramente um manual ou um livro de exercícios, mas sim uma reflexão que prosseguirá em estudos diversos sobre a estética, a filosofia da música até a Histoire génèrale de la musique (História geral da música) escrita por Fétis ao final de sua vida ${ }^{28}$.

Em seu Squisse d'une histoire de l'harmonie (Esboço da história da harmonia), Fétis aborda os "sistemas baseados em fenômenos acústicos, na progressão harmônica e em agregações mecânicas dos intervalos". Pensa sobretudo em Rameau cujos escritos teóricos, na França e em outros lugares, permanecem na base de toda reflexão sobre harmonia29.

Fétis não contesta o princípio da ressonância acústica, mas constata que, referindo-se à natureza, Rameau só pode usar os 6 harmônicos que fornecem diversas consonâncias que se combinam, o acorde perfeito. Com isso, o harmônico 7 não é encontrado nas escalas maiores e menores ${ }^{30}$. Rameau faz derivar todos os outros

27 NT. 0 volume de 178 páginas teve uma tiragem de 50 exemplares (Paris, impresso por Bourgonhe e Martinet, 1840).

28 NT. A "Histoire générale de la musique depuis les temps les plus anciens jusqu'à nos jours" (História geral da música desde os tempos antigos até o presente) é considerada uma obra inacabada, em virtude de seus volumes parcialmente póstumos. Foi publicada em Paris entre 1869-1876 em 5 volumes.

29 seus volumes parcialmente póstumos. Foi publicada em Paris entre 1869-1876 em 5 volumes.

NT. Jean-Philippe Rameau (1682-1764). Compositor e teórico francês e personagem central na história da tonalidade harmônica. 0 enorme esforço de Rameau para iluminar os campos teóricos da harmonia aparece formalmente publicado pela primeira vez no célebre "Traité de l'harmonie réduite à ses principes naturels" de 1722, quando, com cerca de 40 anos, Rameau já acumulava uma considerável bagagem intelectual e experiência artístico-musical. Mas, a partir de então, continuou evoluindo em muitas formulações essenciais que posteriormente aparecem numa série de trabalhos que Rameau continuou a publicar por cerca de mais 40 anos. Assim, como sublinha Rowell, o trabalho de Rameau, como a própria arte da harmonia, estava em um estado de "transformação constante". A cada publicação se seguiam complementos, acréscimos, revisões, respostas às objeções recebidas e novas descobertas, assim "é difícil determinar sua posição final sobre um determinado assunto, porém é duvidoso que existam aspectos da prática do século XVIII que Rameau não tenha analisado em profundidade [...] Não é exagero dizer que a história posterior da teoria harmônica até o começo do século XX consistiu em preencher os vazios que Rameau havia deixado e em completar algumas de suas observações. A ele devemos [...] conceitos que se converteram em fatos aceitos do sistema de harmonia tonal" (ROWELL, 2005, p. 108). Sobre Rameau e seu mundo algumas referências são: Beaussant (1997), Christensen (1993, 2005), Fubini (2002), Girdlestone (1989), Lester (2006) e Moreno (2004).

30 NT. Nesta passagem Wangermée faz menção ao chamado numero senario, enaltecido por Zarlino e Rameau, e também por teóricos mais antigos, (cf. MICKELSEN e RIEMANN, 1977, p. 107-110; WIENPAHL, 1959) como a configuração par excellence do acorde. Nesse espelho da natureza - expressão da ordem, do número e da perfeição - os sons mais graves estão separados por distâncias maiores e os mais agudos estão mais próximos. A fundamental se duplica mais vezes, a quinta só é dobrada uma vez e a terça não é duplicada. 0 senarius é um número chave para os defensores do chamado sensacionismo harmônico (cf. CHRISTENSEN, 1993, p. 215-218). Segundo tal noção, "o poder natural da sensação imediata determina em grande medida o desenvolvimento da prática e da teoria da musical", já que as reações auditivas durante a experiência sonora são os "fatos fisiológicos sobre os quais se baseiam o sentimento estético"(HELMHOLTZ, 1895, p. vii). O senarius mostra a existência de "uma afinidade notável entre sons cujas frequências são proporcionais à sequência dos números inteiros 1, 2, 3, 4, 5 e 6 . A correlação do numero senario [...] com a própria relação entre um fundamental e seus harmônicos mais próximos é incontestável" (MENEZES, 2003, p. 252).

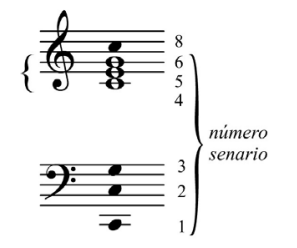


acordes, seja da inversão das primeiras agregações (princípio que Fétis reconhece as virtudes), ou através da superposição ou subposição (abaixo da fundamental) de um certo número de terças maiores ou menores.

Rameau reconhece como "natural" o acorde perfeito maior e assim também o acorde perfeito menor, a partir da construção racional, mas não verificada na realidade, de uma ressonância inferior que determinaria abaixo da fundamental uma série de sons harmônicos, inversamente homólogos aos harmônicos superiores ${ }^{31}$; pela sobreposição das terças Rameau justifica a existência de todos os acordes dissonantes e, particularmente, dos acordes de sétima ou de nona de dominante.

Para compreender o princípio da harmonia, e da própria música produzida a partir daí, Fétis emprega o termo tonalidade, que vê como "o princípio regulador das relações entre sons na ordem sucessiva e na ordem simultânea"32. Na base, estão as escalas musicais, que como mostra Fétis, variam conforme as sociedades. Fétis não leva em consideração apenas os modos gregos ou gregorianos. Também se refere à música indiana, à música chinesa, à música árabe, entre outras.

Da diferença das entonações dos sons e de suas durações mais ou menos prolongadas nasce por intuição seu arranjo em determinada ordem, escreve Fétis no primeiro volume de sua Histoire générale de la musique, dedicada às músicas não europeias. Uma multiplicidade de entonações possíveis existe entre o som mais grave e o mais agudo, mas apenas um certo número apresenta diferenças significativas determináveis.

31 NT. A passagem faz menção ao versado tema do dualismo harmônico: um sistema (para alguns), ou simulacro (para outros), que assegura a existência dos harmônicos inferiores. Em suma, pode-se dizer que o dualismo harmônico se apoia em propriedades ao mesmo tempo intuitivas, especulativas, simbólico-culturais, matemáticas e geométricas buscando uma justificativa unificadora para um dos mais sensíveis calcanhares-de-aquiles da culta teoria musical naturalista: a "tríade menor" (e logo, a "escala menor" e a "tonalidade menor"). Com o esforço argumentativo de vários vultos da teoria musical, tais como Gioseffo Zarlino, Jean-Philippe Rameau, Giuseppe Tartini, Moritz Hauptmann, Arthur von Oettingen, Sigfrid Kar-Elert, Hermann Erpf, Vincent d'Indy e Edmond Costère chegou-se a uma suficiente razão explicativa para a noção (também referida como: dualismo tonal, série harmônica descendente ou invertida, ressonância inferior, etc.). A figura a seguir - redesenhada a partir de Rehding (2008, p. 189-193) - traz uma representação do espelhamento simétrico entre as séries dos harmônicos superiores e inferiores que delineiam o sistema dualista conforme o viés defendido, já na viragem do século XIX para o XX, por Hugo Riemann, um dos mais influentes defensores do "Harmonischer Dualismus" (as notas assinaladas com asterisco não correspondem exatamente as alturas do temperamento igual).

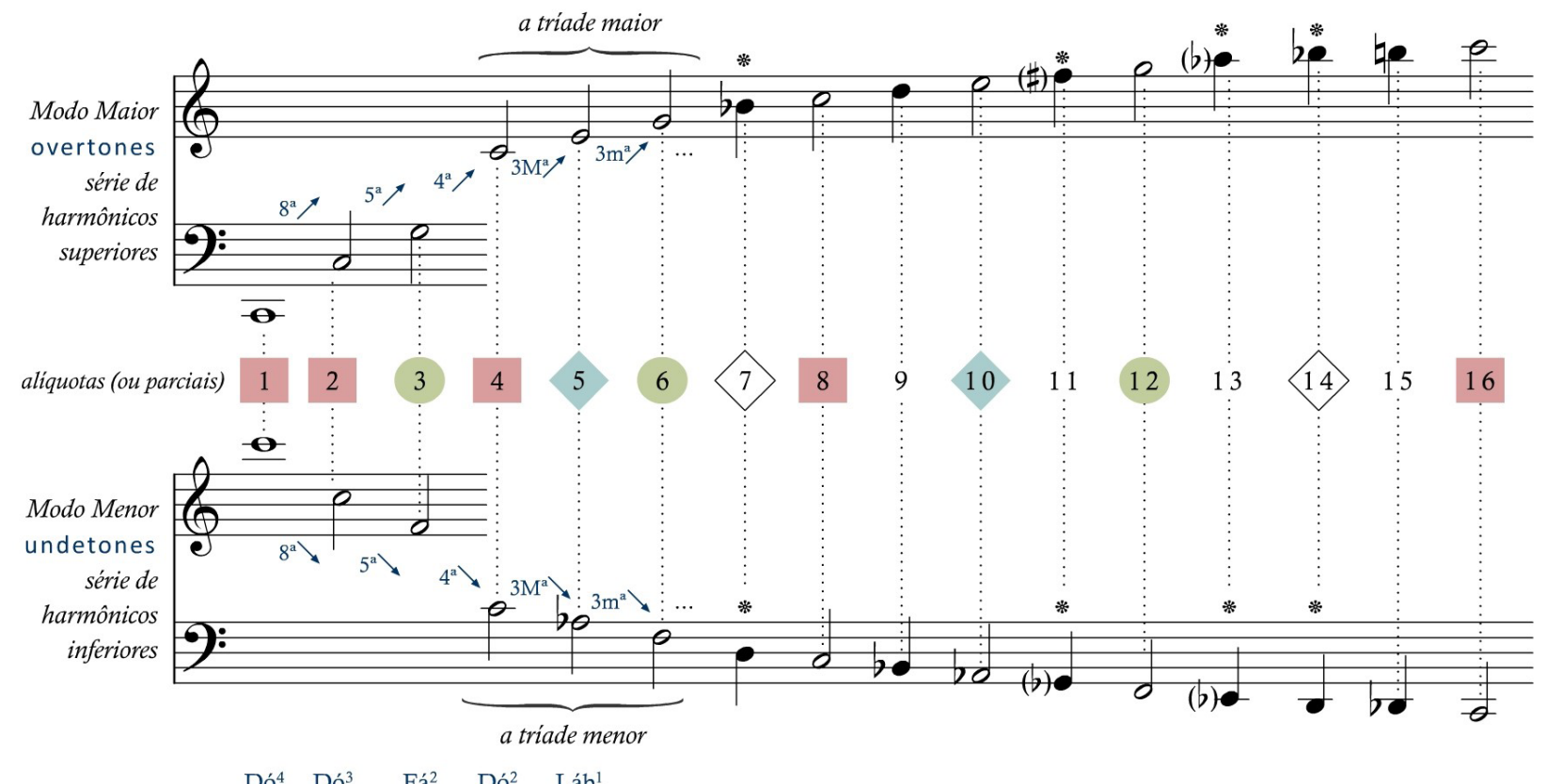

'32 NA. Traité complet de la théorie et de la pratique de l'harmonie, p. vij. 
Conforme os lugares e as épocas, os homens desenvolveram modos diversos de organização melódica ou rítmica:

Independente de diferenças fisiológicas, reitera Fétis, a educação, os costumes e milhões de circunstâncias ignoradas levaram a produzir através da voz humana séries diversas de sons e não de outros e, consequentemente, dar origem a concepções musicais mais ou menos divergentes ent re elas.

É a partir da variedade de escalas que são elaboradas as músicas e sua diversidade:

Para mim, escreve Fétis em seu Squisse d'une histoire de l'harmonie (Esboço da história da harmonia), a tonalidade reside na ordem em que são dispostos os sons da escala, em suas distâncias respectivas e em suas relações harmônicas. A composição dos acordes, as circunstâncias que os modificam e as leis de sua sucessão são resultados necessários desta tonalidade.

O que determina as escalas é o uso que se faz dos sons que as estruturam, e não "os fenômenos acústicos e as leis do cálculo". "O princípio, escreve Fétis, é puramente metafísico"; com isso ele quer dizer que: "nós concebemos esta ordem e os fenômenos melódicos e harmônicos daí decorrentes, por uma consequência de nossa formação e educação"33.

Na música ocidental, que o preocupa particularmente, Fétis considera que os modos utilizados na monodia gregoriana ou na polifonia até o século XVI estão na base do que ele chama de a "antiga tonalidade" ("ancienne tonalité"); em oposição à "tonalidade moderna" ("tonalité moderne") que ele vê nascer na obra de Monteverdi34. Os elementos estruturantes da antiga tonalidade são sua nota final (finalis), a posição variável dos tons e semitons nas escalas em função das diferentes notas finais, e a ausência de sensível na maioria dos modos. Na polifonia, a "antiga tonalidade" conhece somente consonâncias perfeitas (quintas, oitavas, e quartas segundo alguns) e imperfeitas (terças e sextas) e dissonâncias que Fétis chama de "artificiais", pois consistem em uma nota de passagem entre duas consonâncias, ou resultam da prolongação de um som em uma voz enquanto outra opera um movimento.

A harmonia consonante, escreve Fétis em seu Traité, a única que poderia existir na tonalidade do canto chão, não fornecia nenhum meio de introduzir a modulação em música, quer dizer, de colocar em relação de conectividade as gamas musicais entre elas, porque, de acordo com a tonalidade da qual ela tirava seu princípio, ela estava sem tendência, sem atração, e consistia consequentemente em música unitônica. ${ }^{35}$

Partindo deste princípio Fétis avalia a organização harmônica da "tonalidade antiga": ele a descreve essencialmente de maneira negativa em relação às normas da "tonalidade moderna", que é para ele, "a ordem dos fatos melódicos e harmônicos resultantes da disposição dos sons de nossas gamas, quer dizer, da localização do

34 NT. Christensen (2014, p. 61), relembra o fato de que, com a refutação de musicólogos da época, Fétis data as origens da tonalidade moderna em 1605 , mais precisamente a partir da aparição de um acorde de dominante com sétima, sem preparação, nos compassos de abertura de Cruda Amarilli, obra publicada no Quinto Livro de Madrigais de Claudio Monteverdi. Os famosos compassos também são comentados por Shirlaw (1969, p. 345-347).

35 NA. Traité complet de la théorie et de la pratique de l'harmonie, p. xiij. 
semitom entre os $3^{\circ}{ }^{\circ}$ e $4^{\circ}{ }^{\circ}$ graus e entre os $7^{\circ}$ s e $8^{\circ}$ s graus na escala maior", servindo de ponto de partida para a escala menor.

Fétis também reconhece o fato de que, no início do século XVII, as relações de intervalos que no contraponto regiam a organização das diferentes vozes - que por muito tempo se reportavam ao tenor e, posteriormente, ao baixo - cederam lugar quase que inteiramente às relações de acordes. A sobreposição de diversos intervalos acima do baixo passou então a ser percebida como uma entidade global que, como tal, está em relação imediata com as unidades acórdicas que a precedem e que a sucedem; o baixo adquiriu assim o papel funcional de assinalar as alternâncias de tensão e repouso apoiando-se sobre dois acordes fundamentais: o acorde perfeito consonante e o acorde dissonante de sétima de dominante, de onde Fétis deriva todos os demais acordes.

As consequências imediatas da "tonalidade moderna", escreve ele, são as de dar a certas notas um sentimento de repouso que não existe em outras, e de invocar estas notas as terminações das cadências, ou seja, o acorde perfeito; tais notas são a tônica, o quarto, o quinto e o sexto graus ${ }^{36}$; nega-se este caráter de repouso ao terceiro e ao sétimo graus e, consequentemente, também aos seus respectivos acordes perfeitos; da relação entre quarto e sétimo graus decorre uma atração resolutiva que imprime à harmonia dissonante seu caráter próprio e a obriga resolver por uma cadência perfeita ou imperfeita, ou ainda ser seguida por uma modulação, porque não há meio-termo para a harmonia da dominante, deve resolver ou na cadência ou na modulação. ${ }^{37}$

No primeiro caso, na cadência, unicamente na escala maior/menor, a virtude essencial é a de identificar e caracterizar um tom; Fétis a julga tão eficaz nesse papel que acha inútil reforçá-la integrando-a a uma sucessão ampliada de acordes fundamentais (I-IV-V-I), assim como o farão mais tarde Hugo Riemann e outros depois dele. ${ }^{38}$

No segundo caso, a sétima da dominante assinala a passagem de um tom para outro e faz a música ascender ao que Fétis chama de ordem transitônica, aqui a obra pode passar por diversas tonalidades, identificadas na passagem graças à sua dissonância de sétima sobre a dominante (que Schenker chamará mais tarde "dominante de empréstimo") $)^{39}$ para voltar ao tom inicial, confirmado por uma cadência final sobre a tônica.

Se acrescentarmos as diversas inversões aos dois acordes fundamentais, Fétis estima, dispõe-se de um material gerador completo, pois os demais acordes possíveis não são mais do que modificações, que se operam, segundo ele, por procedimentos de prolongação, de antecipação, de alteração e de substituição. ${ }^{40}$ Os três

36 NA. Para Fétis, o sexto grau marca o repouso como primeiro grau do tom relativo menor.

37 NA. Traité complet de la théorie et de la pratique de l'harmonie, p. 249

38 NT. Trata-se de Karl Wilhelm Julius Hugo Riemann (1849-1919), o célebre musicólogo, historiador, compositor e pedagogo alemão lembrado como o proponente do termo-conceito "harmonia funcional", considerado como um dos fundadores da análise musical e um dos mais importantes teóricos da tonalidade e da harmonia. Conforme Abromont e Montalembert (2001, p. 484-485), entre 1872 e 1919, Hugo Riemann escreveu um montante de 62 livros e 209 artigos tratando de diversos assuntos dos campos da história, da teoria, da prática musical e da prática pedagógica.

39 NT. Trata-se do pianista, professor, editor, periodista, crítico e teórico musical nascido na Galícia (hoje parte da Polônia) Heinrich Schenker (1868-1935), bastante conhecido como o proponente da chamada "análise shenkeriana". Em diversas passagens de seu Harmonielehre, o Tratado de Harmonia publicado em 1906, Schenker aborda temas que se relacionam com aquilo que Fétis chamou de "ordem transitônica", notadamente ao longo da seção "Pisocologia do cromatismo e da alteração" (SCHENKER, 1990. p. 360-423). Para uma contextualização das concepções de Schenker acerca da teoria da harmonia, cf. Wason (1995, p. 133-143).

40 NA. Esquisse, p. 174-7. 
primeiros procedimentos resultam da integração do conceito acórdico de práticas já em uso no contraponto tradicional: na sucessão de dois acordes, toda nota que desce ou sobe um grau, pode se prolongar sobre o acorde seguinte, tal nota retarda a constituição normal deste acorde seguinte, e deve ser resolvida segundo determinadas regras; a antecipação é um artifício através do qual se faz ouvir sobre um acorde uma das notas do acorde que deve lhe suceder; toda nota subindo ou descendo o intervalo de um tom na sucessão de dois acordes pode ser alterada para um semitom; se a alteração é ascendente, ela adquire o caráter de uma nota sensível acidental e se resolve necessariamente subindo. Quanto à substituição, que é a "capacidade de ouvir o acorde de sétima de dominante e seus derivados com o sexto grau em lugar do quinto"41, um procedimento que procura explicar o nascimento do acorde de nona de dominante de maneira mecânica, é preciso reconhecer, finalmente, que se trata de algo tão arbitrário quanto a superposição de terças proposta por Rameau. ${ }^{42}$

Em seguida Fétis mostra que, ao se combinarem, as modificações dos acordes fundamentais produzem um grande número de acordes musicais que somente podem ser compreendidos em relação ao próprio tom. Equívocos são criados, então, pelo jogo de enarmonias: o mesmo acorde pode ser resolvido de várias maneiras, movendo-se em direção a outro tom em um dos dois modos. Com isso são descobertas novas possibilidades no domínio da melodia e da harmonia. Fétis deu o nome de ordem pluritônica a esta nova fase da história da tonalidade que vê aparecer em certas obras de Haydn e Mozart e que se desenvolveu depois deles. A multiplicação das atrações tonais "introduzidas em meio às emoções provocadas pela música, o efeito de surpresa provocado pelas sucessões inesperadas de acordes que, não somente afetam a sensibilidade de uma maneira muito viva, mas que proporcionam ao espírito a satisfação de captar e analisar com rapidez de relâmpago o princípio da transformação das relações entre os sons". ${ }^{43}$

Fétis atribui a Monteverdi o mérito de ter sido o primeiro a integrar o intervalo de sétima em um acorde sobre a dominante permitindo assim o nascimento da tonalidade moderna. Mas seus conhecimentos do passado musical eram dependentes dos documentos que the eram acessíveis (edições antigas, raras edições modernas, tratados teóricos, transcrições de obras polifônicas realizadas por ele mesmo), assim, Fétis não conhecia suficientemente o ambiente musical no qual Monteverdi havia criado suas obras.

Em sua tese de doutorado dedicada ao estudo das origens daquilo que chama de tonalidade harmônica (corresponde ao que Fétis chama de "tonalidade moderna" de Fétis), Dahlhaus mostra que, na virada do século XVI para o XVII não existe fronteira rígida entre a escrita por intervalos e a escrita por acordes. Dahlhaus mostra que as mudanças intervindas pelo ano de 1600, foram anunciadas por tendências

\footnotetext{
41 T. Em linhas gerais, no item 365 do Quarto Livro (Geração e classificação dos acordes) do Traité..., Fétis argumenta que, a "substituição" ocorre quando, apenas em acordes do tipo sétima de dominante e suas inversões, a sexta nota da escala toma lugar da quinta. Assim, quando o acorde de sétima está escrito a cinco vozes, a saber: sol, si, ré, fá, sol, a nota sol da parte mais aguda é substituída pela nota lá. Surge então o "acorde de nona da dominante" que, conforme o modo, será maior (nota lá natural) ou menor (nota lá bemol).

42 NT. Respondendo aos comentários críticos endereçados a este procedimento "mecânico", Fétis escreve que a "substituição" se efetua "em virtude de uma lei que não nos é mais conhecida do que outros fenômenos harmônicos, mas nossa organização aceita seus efeitos, e nosso intelecto apreende o mecanismo" (em artigo para a Revue et Gazette musicale publicado 1844 e reimpresso em uma nota anexada ao Traité complet de la théorie et de la pratique de l'harmonie [p.250], à partir da terceira edição.

43 NA.Traité complet de la théorie et de la pratique de l'harmonie, p. xvij.
} 
pré-existentes consideradas menores ao longo do século XVI, em relação às normas do contraponto rigoroso 'à maneira flamenga', progressivamente reunidas e consequentemente fortalecidas. ${ }^{44}$

Assim, percebe-se que Monteverdi não transformou sozinho a música, do contraponto à antiga para a harmonia moderna, senão que, em seus últimos livros de madrigais, Monteverdi introduziu tantas exceções às regras tradicionais que merece ser reconhecido como o primeiro músico "moderno". Em sua época, Monteverdi poderia ser reprovado por recorrer a notas de passagem acentuadas, por ter renunciado a preparação ou a resolução de certas dissonâncias segundo a regra do movimento conjunto e de ter praticado de maneira abrupta a dissonância "nota contra nota". Pode-se hesitar, no entanto, em classificar o emprego que Monteverdi faz de tal dissonância de sétima, nota contra nota, em um acorde ao invés de em uma dissonância intervalar e Monteverdi não pratica o encadeamento de acordes dissonantes e consonantes. No entanto, Fétis não se equivocou em ver em Monteverdi um anunciador da nova tonalidade e o primeiro músico moderno, pois Monteverdi escreveu uma música cujos acentos expressivos, paixões e efeitos dramáticos, estão ligadas às tensões criadas pelo novo uso da dissonância e que inauguram verdadeiramente uma nova música.

Em seus trabalhos, Fétis coloca em evidência o papel privilegiado da tônica em meio aos outros graus da escala, mostra que uma tensão se exerce permanentemente em sua direção, proveniente de acordes apoiados sobre graus privilegiados, particularmente a dominante; mostra a importância a este respeito do acorde de sétima da dominante cuja dissonância orgânica exerce uma função particular; mostra, enfim, que estas diversas relações podem ser cromaticamente transpostas sobre todos os graus da escala graças à modulação.

Ao que parece então, Fétis foi assim o primeiro a tentar caracterizar aquilo que Riemann, Schenker e, nesta linha, também Célestin Deliège ${ }^{45}$, chamaram de harmonia tonal e que Carl Dahlhaus chamou de tonalidade harmônica. Certamente se poderia criticar Fétis por ter entendido o conceito de tonalidade às estruturas da polifonia da Idade Média e da Renascença, baseadas em modos do canto chão e mesmo àquelas músicas populares não-europeias, estabelecidas em modos específicos. Sem dúvida, o termo "modalidade" Ihes conviriam melhor. A terminologia de Fétis respondeu à sua preocupação em englobar numa explicação única e racional todas as variantes de organização de diferentes escalas.

No mesmo espírito, suas análises da 'tonalidade moderna' visam definir as constantes estruturais assim como suas variantes históricas. Para Fétis, efetivamente, a música tonal é uma realidade que não pode ser estudada de maneira diacrônica.

Aplicando a lógica do sistema que havia descriptografado o mecanismo através de sua história, Fétis pôde, nos anos de 1830, tirar conclusões a respeito da multi-

44 NA. DAHLHAUS, Carl. La tonalité harmonique. Étude des origines. Liège, Mardaga, 1977; DAHLHAUS, Carl. Studies in the origin of harmonic tonality. Oxford: Princeton University Press, 1990. A edição em alemão, Untersuchungen über die Entstehung der harmonischen Tonalität, remonta à 1967. Trata-se de um "estudo completo e documentado em fontes primárias, explorando principalmente as dimensões técnicas, teóricas e analíticas, assim como estéticas e históricas, que proporcionaram o nascimento e o desenvolvimento da tonalidade ocidental" (ABROMONT e MONTALEMBERT, 2001, p. 504).

45 NT. DELIĖGE, Célestin. Les Fondements de la musique tonale: une perspective analytique post-schenkerienne. Paris: Lattès, 1984. O musicólogo e compositor belga Célestin Deliège (1922-2010) é lembrado como um dos últimos grandes representantes do modernismo pós-guerra e um influente teórico da música instrumental contemporânea. Foi professor de análise musical no Conservatoire royal de Musique de Liège (Bélgica) e, ao longo de mais de 40 anos, publicou diversos artigos e livros. 
plicidade das possibilidades de modulação. Fétis imaginou então uma quarta e para ele última fase da evolução da tonalidade que chamou de ordem omnitonica e caracterizou pela "universalidade das relações realizadas pela exploração da enarmonia simples ou resultante de alterações múltiplas dos intervalos dos acordes". Aqui, diz Fétis, é como se o compositor quisesse responder um problema mais ou menos assim: "Dada uma nota, encontrem-se combinações e fórmulas harmônicas tais que elas possam resolver em todos os tons e em seus diversos modos". ${ }^{46}$

A maioria dos criadores comprometidos com a prática da modulação permanente não fazem nenhuma referência aos trabalhos teóricos de Fétis, salvo Franz Liszt que viveu em Paris e que, ainda jovem, assistiu atentamente o Cours de filosophie musicale et d'histoire de la musique que Fétis ministrou em 1832. Segundo o que o próprio Fétis relatou na Revue musicale, Liszt declarou, após ouvir exemplos de resoluções harmônicas audaciosas da ordem omnitonica:

O Senhor Fétis prevê o momento em que o ouvido estará habituado com a multiplicidade destas resoluções de uma nota, que o resultado desta ordem omnitonica será a aniquilação total da escala em certos casos, e a origem de uma divisão acústica da escala musical em doze semitons iguais, devido a igualdade das tendências. ${ }^{47}$

As harmonias estranhas que ilustraram a exposição e a previsão da musica de doze sons suscitaram espanto aos ouvintes mais incrédulos, mas grande interesse entre alguns, como Franz Liszt.

A priori, Fétis não sente nenhuma inquietação frente à perspectiva de uma máxima exploração do princípio da modulação. Contudo, analisa com muita acuidade a contribuição da ordem omnitonica para a criação musical.

A unidade tonal existe sempre ao momento em que o acorde se faz entender, pois o espírito capta perfeitamente as relações de sons alterados, e a sensibilidade, longe de ser ferida, as recebe prazenteiramente; mas as afinidades dos acordes, assim modificados por todas as gamas, não se manifestam até o momento em que uma das resoluções se faz entender. Então, a incerteza se dissipa, e esta sucessão de acordes e tonalidades que se manteve em segredo do artista até o momento em que se fez entender causa, por um lado, uma emoção de surpresa misturada com prazer na sensibilidade; e por outro, satisfaz à inteligência, que ressarce imediatamente todos os pontos de contato por onde ocorreu a transformação tonal. ${ }^{48}$

Fétis completou suas previsões sobre o futuro da música imaginando que uma evolução paralela àquela da harmonia poderá afetar o ritmo e o timbre:

Quem ousará afirmar, dizia em 1832, que o ritmo chegaria ao ponto em que chegou? [...]. Tenho o pressentimento de que o que foi feito com a harmonia, e consequentemente com a melodia que está intimamente ligada à ela, far-se-á para o ritmo ${ }^{49}$ Nós estamos, talvez, ainda na ordem uniritmica, da mesma forma que estávamos limitados à ordem unitônica no século dezesseis. Quem sabe se não será encontrada, qualquer dia, a ordem transritmica, depois a pluriritmica e, enfim, a omniritmica? A mudança de ritmo, no ponto em que estamos, não é ainda

46 NA. Esquisse, p. 176.

47 NA. Revue musicale, 1833 , p.796-7.

48 NA. Traité complet de la théorie et de la pratique de l'harmonie, p. xlix.

49 NA. $O$ curso de 1832 compreende diversos capítulos originais sobre o compasso, o movimento e o ritmo. Cf. Revue musicale, 1832, p.155-8, 162-4. 
uma necessidade, como a mudança de tom no tempo da ordem unitônica, não é ainda algo solicitado pelo ouvido; mas encontrada a necessidade de transição do ritmo como foi constatado com a tonalidade a partir do acorde de sétima de dominante, e a mudança se tornará um elemento de uma sensação particular, como a regularidade é hoje elemento de uma outra. Uma vez descoberto este elemento, combinações pluritmicas e finalmente omniritmicas surgirão em breve.

“Existe algo a mais que o ritmo e a tonalidade em música?, acrescenta Fétis, o timbre, a sonoridade não são também elementos dessa arte? Quem sabe o que resta para descobrir sobre isso? Quem sabe o que poderemos fazer com as vozes e instrumentos agrupando-os em todas as combinações possíveis?" Fétis concluiu então: "[...] há um futuro, um longo futuro, nas combinações materiais dos meios da arte, e além deste futuro há o gênio que é o infinito". ${ }^{50}$

Em seus trabalhos teóricos, Fétis esteve sempre aberto à inovação. Contudo, por suas críticas à atualidade, frequentemente se mostrou aos olhos de seus contemporâneos como um juiz conhecedor, mas reacionário. Ele considerava Berlioz, Schumann, Liszt e Wagner como mestres, "artistas sérios que possuem uma incontestável habilidade em recursos de harmonia e instrumentação e que aspiravam à realização do belo em suas músicas", mas Fétis os censurava por "se jogarem no bizarro com medo de cair no comum"; ele não poupou suas críticas em diversas ocasiões.

Denunciou particularmente "a progressão incessante das tendências à modulação" e, por conseguinte, "a incerteza que reina sem cessar sobre a tonalidade, pela frequência das resoluções harmônicas em tons diferentes daqueles que deveriam ocorrer naturalmente". ${ }^{51}$ Denunciou também "o sistema de emaranhamento, pelo qual, de suspensão em suspensão, de incidência em incidência, se prolonga indefinidamente a textura dos períodos: de tal sorte que eles ocorram como os papéis sem fim que se fabricam mecanicamente, e que a terminação não parece ser necessária" ${ }^{52}$

A principal crítica endereçada por Fétis a estes músicos, era a ameaça ao próprio princípio da tonalidade através da utilização sistemática e exclusiva de procedimentos da ordem omnitonica.

Tal crítica não está distante daquela que Arnold Schoenberg posteriormente endereçou aos compositores que multiplicaram os acordes "vagabundos" 53 e as modulações errantes, não estruturadas em um plano global, e que assim colocavam em perigo "a ideia de um centro de gravidade tonal". Schoenberg dizia que, vagante assim, a tonalidade não seria mais capaz de exercer suas funções essenciais de unificação e de articulação na construção de uma obra, porém, antes de abandoná-la, primeiro seria necessário encontrar o meio de substituir este duplo papel. Dessa forma Schoenberg justifica a utilização da composição com doze sons e a técnica serial.

Fétis nunca imaginou, contudo, que seria possível extrapolar o âmbito da to-

50 NA. Revue musicale, 1832, p.198.

51 NA. Traité complet de la théorie et de la pratique de l'harmonie, p. 200

52 NA. Biographie universelle des musiciens, $2^{\mathrm{a}}$ edição, t.1, p. viij.

$53 \mathrm{Em}$ seu vocabulário técnico, Schoenberg emprega expressões como "roving harmony" ou "vagrant harmony", que literalmente podem ser compreendidas como aquela harmonia que se desloca de lugar em lugar, uma harmonia vadia, vagabunda, mendiga. Cf. Dudeque (2005, p. 80-84 e 246). Numa conhecida passagem de seu Harmonielehre, Schoenberg compara o "complexo sonoro" si-ré-fá-lab (o acorde diminuto), "por sua própria natureza", com um "vagabundo andarilho", um "não morador de parte alguma" e o efeito da "modulação" com "uma excursão [Ausflug]" (SCHOENBERG, 2001, p. 286 e 511). Em seu "Funções estruturais da harmonia" dedica um capítulo aos "vagierende Akkorde" ("Acordes errantes") e uma célebre seção, na qual encontramos também a ideia de "motivo errante", ao tema da "Harmonia Errante" (SCHOENBERG, 2004, p. 66-71 e 187-214). 
nalidade. "Além da ordem omnitonica, nada mais há", sentenciou. ${ }^{54}$ É por isso que Fétis almeja uma coexistência pacífica entre as quatro ordens.

É permitido ao compositor permanecer na unidade absoluta da tonalidade, se o sentimento estético exige que a música seja calma, doce ou religiosa. Se a transição lhe é necessária, ele a encontra na harmonia dissonante natural, isenta de qualquer alteração. Mas se a simples modulação não é suficiente, e se lhe é necessária uma poderosa comoção, pelo efeito de uma mudança inesperada de tonalidade, a enarmonia pluritônica lhe oferece os meios. Enfim, se ele deve agitar paixões ardentes, ou exprimir sentimentos de uma profunda melancolia, a ordem omnitonica the abre o infinito de seus recursos.

É assim, dizia Fétis, que "a arte realiza em sua mais completa acepção a unidade na variedade e a variedade na unidade". ${ }^{55}$ Mas, na década de 1840, Fétis teve que reconhecer que o rumo tomado pela música não seguia este caminho ecumênico:

(...) após uma longa reserva, os artistas se atiraram ao abandono na carreira da música modulante, escreveu Fétis em seu Traité ${ }^{56} \mathrm{e}$ tal é o abuso das fórmulas desta música nos últimos anos, que é possível afirmar que a unidade tonal está agora absolutamente banida da arte. Quando eu previa e anunciava este último resultado da direção harmônica da música, em meu curso de filosofia desta arte (em 1832), eu não acreditava que este resultado estivesse tão perto de nós.

Apesar de uma forte polêmica na década de 1830 a propósito do virtuosismo pianístico, Franz Liszt sempre teve grande estima por Fétis. Em uma carta que the endereçou em 1859, enquanto estava plenamente consciente das críticas que Fétis lhe fazia, Liszt lhe disse que sempre se recordava de seus cursos sobre "a omnitonia e a omniritmia" e que tirara partido de seus ensinamentos em sua música. ${ }^{57}$ Cerca de vinte anos mais tarde, após tomar conhecimento da notícia muito elogiosa, mas reservada sobre certos pontos, que Fétis the consagrara na segunda edição de sua Biographie universelle des musiciens, Liszt escreveu a um de seus amigos um depoimento de estima e também de reservas em relação a Fétis:

De todos os teóricos que me são conhecidos, o Senhor Fétis foi quem melhor pressentiu e definiu o progresso da harmonia e do ritmo em música; sobre tais pontos principais, lisonjeio-me de estar em perfeito acordo com ele [...]. Segundo sua teoria, a arte deve progredir, se desenvolver, se enriquecer, revestir-se de formas novas; mas, na prática, ele hesita, recusa - ou, pelo menos, exige que a 'transformação' se realize sem a perturbação de hábitos adquiridos e de maneira a encantar imediatamente todas as pessoas. Quisera Deus que fosse assim. ${ }^{58}$

Fétis não terá sido o único teórico lúcido a se fechar, em nome do seu sistema, diante da evolução das realidades musicais. No entanto, seria injusto não reconhecer seus méritos como o primeiro teórico da harmonia tonal.

54 NA. Revue musicale, 1832, p.186.

55 NA. Traité complet de la théorie et de la pratique de l'harmonie, Préface, p. xlix.

56 NA. Traité complet de la théorie et de la pratique de l'harmonie, p. 196.

57 NA. Carta de 17 de setembro de 1859, Franz Liszt in seinen Briefen. Eine Auswahl, Ed. H. R. Jung (Berlin, 1987), p. 169, citado por Klara Moricz, "The ambivalent Connection between Theory and Practice in the Relationship of F. Liszt and F.-J. Fetis", Studia musicologica, t. 35 (1993-1994), p. 416.

58 NA. Carta de 8 de novembro de 1867, (La Mara, Franz Liszt Briefe, t.2 [Leipzig, 1893], p. 111-112). 


\section{Referências}

ABBAGNANO, Nicola. Dicionário de filosofia. São Paulo: Mestre Jou, 1982.

ABROMONT, Claude e MONTALEMBERT, Eugène de. Teoría de la música: una guía. México, D.F.: Fondo de Cultura Económica, 2001.

ARLIN, Mary I. Fetis' contribution to practical and historical music theory. Revue belge de Musicologie,v. 26, p. 106-115, 1973.

BEAUSSANT, Philippe. Jean-Philippe Rameau (1683-1764). In: MASSIN, Jean \& Brigitte. História da música ocidental. Rio de Janeiro: Nova Fronteira, 1997. p. 493-499.

BENÉVOLO, Caio. A polêmica Forkel-Rousseau. Debates - Cadernos do Programa de Pós-Graduação em Música do Centro de Letras e Artes da UNIRIO, Rio de Janeiro, CLA/UNIRIO, n. 7, p. 57-97, 2004.

BERRY, David Carson. The meaning(s) of "without": an exploration of Liszt's "Bagatelle ohne Tonart". 19th-Century Music, v. 27, n. 3, p. 230-262, Spring, 2004.

BINGHAM, Alfred J. Marie-Joseph Chénier and french culture during the french revolution. The Modern Language Review, v. 61, n. 4, p. 593-600, Oct. 1966.

BROWN, Matthew. Explaining Tonality: Schenkerian theory and beyond. Eastman Studies in Music 27. Rochester: University of Rochester Press. 2005.

CHAILLEY, Jacques. Traité historique d'analyse musicale. Paris: Alphonse Leduc, 1947.

CHRISTENSEN, Thomas. Fétis and emerging tonal consciousness. In: BENT, Ian (Ed.). Music theory in the age of romanticism. Cambridge: Cambridge University Press, 1996, p. 37-56.

CHRISTENSEN, Thomas. Fétis and emerging tonal consciousness. In: BENT, Ian (Ed.). Music theory in the age of romanticism. Cambridge: Cambridge University Press, 1996, p. 37-56.

CHRISTENSEN, Thomas. Fétis and the origins of tonality. In: EUROPEAN MUSIC ANALYSIS CONFERENCE, EUROMAC 8, 2014, Leuven. Abstracts... Leuven, 2014. p. 61.

CHRISTENSEN, Thomas. Rameau and musical thought in the enlightenment. Cambridge: Cambridge University Press, 1993.

CHRISTENSEN, Thomas. Rameau and the rhetoric of music theory. Em Pauta, Porto Alegre, v. 16, n. 27, p. 5-24, jul./dez. 2005. 
CLOUTIER, Diane. Revue musicale, 1827-1835. Ann Arbor, Mich: U.M.I., 1991.

CORREAA, Antenor Ferreira. Estruturações harmônicas pós-tonais. São Paulo: Ed. UNESP, 2006.

DAHLHAUS, Carl. La idea de la música absoluta. Barcelona: Idea Books, 1999.

DAHLHAUS, Carl. Studies in the origin of harmonic tonality. Oxford: Princeton University Press, 1990.

DAHLHAUS, Carl. Tonality. In: SADIE, Stanley (Ed.). The New Grove Dictionary of Music and Musicians. London: McMillan, 1980. v. 19, p. 51-55.

DAMSCHRODER, David. Thinking about harmony: historical perspectives on analysis. Cambridge University Press, 2008.

DUDEQUE, Norton E. Music theory and analysis in the writings of Arnold Schoenberg. Aldershot: Ashgate, 2005.

FÉTIS, François-Joseph. A música ao alcance de todos. Ou noticia succinta de tudo o que é necessário para ajuizar e fallar d'esta arte sem a ter profundado. Porto: Casa de Cruz Coutinho, Editor, 1858.

FÉTIS, François-Joseph. Traité complet de la théorie et de la pratique de l'harmonie: contenant la doctrine de la science et de l'art. 8. ed.Paris: G. Brandus et S. Dufour, 1864. FREITAS, Sérgio Paulo Ribeiro de. Que acorde ponho aqui? Harmonia, práticas teóricas e o estudo de planos tonais em música popular. Doutorado em Música. Instituto de Artes, Unicamp, Campinas, 2010.

FUBINI, Enrico. Los enciclopedistas y la música. Valência: Ed. Universitat de Valência, 2002.

GIRDLESTONE, Cuthbert Morton. Jean-Philippe Rameau: his Life and work. New York: Dover Publications, Inc, 1989.

GONSALVES, Augusto Lopes. Uma viagem musical à Itália no século XVIII. Revista Brasileira de Música, Rio de Janeiro: Instituto Nacional de Música da UFRF, v. 1, n. 1, p. 24-33, março 1934.

GRANT, Cecil Powell. The real relationship between Kirnberger's and Rameau's "Concept of the Fundamental Bass". Journal of Music Theory, v. 21, n. 2, p. 324-338, Autumn, 1977.

GUBERNIKOFF, Carole. "Escuta: lugar das multiplicidades musicais" In : VOLPE, Maria Alice (Org.). Teoria, crítica e música na atualidade. Série Simpósio Internacional de Mu- 
sicologia. Rio de Janeiro: Universidade Federal do Rio de Janeiro. Escola de Música. Programa de Pós-graduação em Música, 2012.

HELMHOLTZ, Hermann von. On the sensations of tone as a physiological basis for the theory of music. London: Longmans, Green, And Co. 1895.

HYER, Brian. Tonality. In: CHRISTENSEN, Thomas (Ed.). The Cambridge history of western music theory. Cambridge: Cambridge University Press, 2006. p. 726-751.

KIRNBERGER, Johann Philipp. The true principles for the practice of harmony. Tradução: David W. Beach e Jurgen Thym. Journal of Music Theory, v. 23, n. 2, p. 163-225, Autumn, 1979.

KOSAR, Anthony Jay. François-Joseph Fetis' Theory of Chromaticism and Early Nineteenth Century Music. Ohio State University 1984.

LE GOFF, Jacques. História e memória. Campinas: Ed. da Unicamp, 2003.

LESTER, Joel. Rameau and eighteenth-century harmonic theory. In: CHRISTENSEN, Thomas (Ed.). The Cambridge history of western music theory. Cambridge: Cambridge University Press, 2006. p. 753-777.

LESTER, Joel. Rameau and eighteenth-century harmonic theory. In: CHRISTENSEN, Thomas (Ed.). The Cambridge history of western music theory. Cambridge: Cambridge University Press, 2006. p. 753-777.

LOYA, Shay. Liszt's Transcultural modernism and the hungarian-gypsy tradition. Rochester: University of Rochester Press, 2011.

MENEZES, Flo. A acústica musical em palavras e sons. São Paulo: Ateliê Editorial, 2003.

MICKELSEN, William Cooper e RIEMANN, Hugo. Hugo Riemann's theory of harmony a study by William C. Mickelsen and History of music theory, book III by Hugo Riemann. Lincoln: University of Nebraska Press, 1977.

MORENO, Jairo. Musical representations, subjects, and objects: the construction of musical thought in Zarlino, Descartes, Rameau and Weber. Bloomington: Indiana University Press, 2004.

MÓRICZ, Klára. The ambivalent connection between theory and practice in the relationship of F. Liszt \& F.- J. Fétis. Studia Musicologica Academiae Scientiarum Hungaricae, n. 35, v. 4, p. 339-420, 1994.

NATTIEZ, Jean-Jacques. Harmonia. In: ENCICLOPÉDIA Einaudi v. 3. Porto: Imprensa Nacional-Casa da Moeda, p. 245-271, $1984 a$. 
PRIORE, Irna. O desenvolvimento da teoria musical como disciplina independente: princípio, conflitos e novos caminhos. Opus, Porto Alegre, v. 19, n. 1, p. 9-26, 2013. REHDING, Alexander. Hugo Riemann and the birth of modern musical thought. Cambridge: Cambridge University Press, 2008.

REIS, Sandra Loureiro de Freitas. A "Ópera Tiradentes" de Manuel Joaquim de Macedo e Augusto de Lima. Latin American Music Review / Revista de Música Latinoamericana, v. 14, n. 1, p. 131-144, Spring - Summer 1993.

ROWELL, Lewis. Introduccion a la filosofia de la musica. Barcelona: Editorial Gedisa, 2005.

RUEB, Franz. 48 variações sobre Bach. São Paulo: Companhia das Letras, 2001.

SALAZAR, Adolfo. Introducción (e contracapa). In: FORKEL, Johann Nikolaus. Juan Sebastian Bach. Tradução: Adolfo Salazar. México: Fondo de Cultura Económica, 1993.

SANTAELLA, Lucia. Matrizes da linguagem e pensamento: sonora, visual, verbal. São Paulo: Iluminuras, 2001.

SASLAW, Janna K. Gottfried Weber and the concept of Mehrdeutigkeit. Columbia University, 1992. (Tese de Doutorado).

SCHELLHOUS, Rosalie. "Fétis's tonality as a metaphysical principle: hypothesis for a new science." Music Theory Spectrum, v. 13, n. 2, p. 219-240. 1991.

SCHENKER, Heinrich. Tratado de armonia. Madrid: Real Musical, 1990.

SCHOENBERG, Arnold. Funções estruturais da harmonia. São Paulo: Via Lettera, 2004.

SCHOENBERG, Arnold. Harmonia. São Paulo: Ed. da Unesp, 2001.

SHIRLAW, Matthew. The theory of harmony: an inquiry into the natural principles of harmony, with an examination of the chief systems of harmony from Rameau to the present day. New York: Da Capo Press, 1969.

SIMMS, Bryan. Choron, Fétis, and the theory of tonality. Journal of Music Theory, v. 19, n. 1, p. 112-138, Spring 1975.

SQUEFF, Enio. A música na Revolução Francesa. Porto Alegre: L\&PM, 1989.

WANGERMÉE, Robert (Org.). Fétis, François-Joseph,. Correspondance. Sprimont: Mardaga, 2006.

WANGERMÉE, Robert e ELLIS, Katharine. "Fétis: (1) François-Joseph Fétis". In: SADIE, 
Stanley e TYRRELL, John (Ed.). The New Grove Dictionary of Music and Musicians. London: Macmillan Publishers. 2001.

WANGERMÉE, Robert. François-Joseph Fétis, musicologue et compositeur. Contribution à l'étude du goût musical au XIXe siècle. Bruxelles: Palais des Académies, 1951.

WANGERMEE, Robert. Le concept de tonalite selon Fetis. Revue belge de Musicologie / Belgisch Tijdschrift voor Muziekwetenschap, v. 52, p. 35-45. 1998.

WASON, Robert W. Musica practica: music theory as pedagogy. In: CHRISTENSEN, Thomas (Ed.). The Cambridge history of western music theory. Cambridge: Cambridge University Press, 2006. p. 46-77.

WASON, Robert W. Viennese harmonic theory from Albrechtsberger to Schenker and Schoenberg. Rochester, NY: University of Rochester Press, 1995.

WIENPAHL, Robert W. Zarlino, the Senario, and tonality. Journal of the American Musicological Society, v. 12, n. 1, p. 27-41, 1959. 